\title{
The Important Role of Career Planning in the Development of College Students
}

\author{
Peng Xiaojiang \\ Shaanxi Xueqian Normal Universty, Shaanxi Xi'an, China, 710100
}

Keywords: Career planning, College students' life development

\begin{abstract}
The theory of career planning was introduced into China from European and American countries. It refers to a practical planning and design of a certain career and the future career development. It is a complete process of making reasonable implementation methods and constantly striving for it through the deep self-understanding, selection of career goals and the formulation of reasonable implementation methods. In view of the realistic situation of innovation and competition in today's society, it is extremely important for a college student to formulate reasonable, practical and scientific personal short-term, medium-term and long-term career planning from the moment he enters school. Career planning is not only beneficial for graduation and employment at present, but also for the long-term development of students. This paper intends to explore the role of career planning in college students' life development from the four aspects.
\end{abstract}

\section{Introduction}

\subsection{An Overview of the Importance of Career Planning Theory}

The career planning theory started late and developed slowly in China. It is a theory introduced into China from European and American countries in the mid-1990s. Career planning refers to the practical and feasible planning and design for the development of a certain career and future career that a person will engage in. Through a profound understanding of himself, the selection of career goals, the formulation of reasonable implementation methods, and the continuous efforts for it, all of this is a complete process. As a college student, it is extremely important to make reasonable, feasible and scientific personal short-term, medium-term and long-term career planning as soon as you enter the university. A good career planning is not only beneficial to the current graduate employment, but also positive and important for the long-term life development of college students. Nowadays, with the increasingly fierce competition in society,how to distinguish oneself from the numerous graduates? How to preserve an individual's place in society? How to make one's life development plan step by step and more scientific?It is a difficult problem for every college student. Historically, Chinese people pay attention to making preparations for the rainy season.The same is true for college students in terms of their academic and life paths as well as their long-term development plans. They should make plan well in advance and formulate the methods and measures to complete the implementation, so as to make themselves not blind and helpless in their current studies and future life development. The scientific and effective formulation of career 
planning is bound to make a person smooth on the road of life development, and it is also of great significance to promote the healthy, harmonious and all-round development of his life. Therefore, we should pay attention to and understand the important role of career planning and it is the key to the problem.

\subsection{In Recent Years, the Development of Career Planning in Colleges and Universities of China}

In recent years, the education and training of College Students'career planning, and have also increased the introduction and training of teachers for college students' career planning training. However, the training and research on college students' career planning is still not in-depth, and there are limitations in training and research.Career planning of college students is a long-term and consistent process, and it is also a comprehensive subject covering a large number of subjects. For example, career planning education includes education, psychology, sociology, human resources management theory and other contents. In view of the complexity of career planning and its importance to college students' life development, colleges and universities should gradually establish a career planning education and training system with their own characteristics, and gradually conduct in-depth, scientific and feasible career planning training education and research, so as to truly help a college student to formulate a career planning that fits the development of one's own life.

\subsection{Problems in Career Planning Education in China}

These problems are mainly concentrated in the vague concept of career planning of the public, many colleges and universities and college students do not attach importance to career planning; in Colleges and universities, the curriculum time of career planning education is generally very short. They do not realize that career planning is a long and continuous process. Teachers of career planning in universities are not professional, and their study of career planning theory is not very profound and systematic. Nowadays, the world and society are the innovation and competition of talents. If colleges and universities can intensify the reform and attach importance to the important role of career planning education in graduate employment, life planning and life development of College students, then the talents trained by the state are the real available talents, and all aspects are sound and good.

\section{Important Significance and Measures Strengthening of Career Planning Education}

Specifically, college students' career planning plays an important guiding and promoting role in their life development. It mainly manifests in the following aspects: Firstly, to do a good job in college students' career planning education and training is conducive to enhancing their social adaptability and competitiveness, so as to make their life path develop scientifically and orderly. Nowadays, the society is changing rapidly, and the competition is becoming increasingly fierce. How can we make ourselves competitive in the society is a practical problem for college students. Through scientific and reasonable career planning education, college students from their own reality, real and professional for their situation, analyze advantages and disadvantages, according to the requirements of the development of society and timely adjust and develop your own career path of development, constantly to improve their social adaptability and competitiveness, prompting the individual's life trajectory to scientific and orderly.

Secondly, a good career planning of college students can help them clarify their life goals and avoid blind development. Everyone has dreams. Some people are only passionate about dreams at 
the moment. How to keep their dreams alive and how to make their dreams come true step by step? This should be a problem that every college student needs to think about and solve. It is not easy to achieve a dream, and it is even more difficult to achieve a dream. Once you set up your dream, you should use professional career planning knowledge to plan and manage it. Career planning theory is an effective guiding theory for college students at the beginning of their life. through the analysis of theory of career planning and support, according to the present practice of individuals and the future development direction and needs, to develop practical strategies and paths, achieving personal goals, make oneself of the development of targeted and operability, avoid blind development.

Thirdly, a good career planning of college students can help them to make a self-recognition in a timely manner. and better adapt to the needs of today's society and world development, so as to truly realize their personal life value. Career planning theory is an important part of self that is representative of the Holland vocational interest test, students can according to this kind of science, has a strong operational theoretical knowledge to understanding themself, analysis the advantages and disadvantages of the individual, put personal interests and weaknesses.In order to meet the needs of the current society and the world competition, we need to constantly improve ourselves, cultivate ourselves and make ourselves have a strong comprehensive quality and ability.

Fourthly, a good career planning of college students can help college students timely adjust their short-term, medium-term and long-term development paths of personal development, and truly enable the development of personal life to develop scientifically and harmoniously. College students' career planning education is a long-term, continuous and continuous training process, and it is not an on-going thing. therefore, in this gap in the process of continuous education and training, college students can according to oneself and all kinds of changes of the outside world, constantly adjust short-term, medium-term and long-term personal life development trajectory, make it a better guide their own scientific and sound development, so as to make their own in a competitive position, so as to make the individual life to scientific development, harmonious and orderly progress. Therefore, in this uninterrupted continuous education and training process, college students can adjust their short-term, medium-term and long-term development track of life development according to various changes from themselves and the outside world.,making it better to guide its own scientific development, so as to make itself in a competitive position, so that the development of personal life can be scientifically, harmoniously and orderly.

Finally, from the perspective of rational allocation of social talents, career planning is conducive to the rational allocation of human resources for college students. Under the conditions of market economy, how to reasonably allocate human resources has become a prominent social issue. It is obvious that the planning method of the past monopoly cannot adapt to the needs of the new situation. And vocational guidance is to change this phenomenon, understand the characteristics of the various professional user unit and usage, understand the psychological and physiological characteristics of workers, so that the schedule is reasonable, science, and use it properly and effectively, make the individual talent, knowledge, interest and consistent of the work, the personnel suitable, functions, of men and use; It enables graduates to fully understand the needs of social development for talents, so as to find the position where they can give full play to their talents and achieve the goal of reasonable allocation of human resources.

\section{The full text of Conclusions and research prospects}

To sum up, a good career planning for college students is conducive to enhancing their social adaptability and competitiveness, so that they can develop scientifically. It helps college students to define their personal life goals and avoid blind development. It helps college students to recognize themselves in time and better adapt to the needs of today's society and the world. It is helpful for 
college students to adjust their personal development path at the right time, and finally achieve scientific and harmonious development. From the point of view of students growth and success, if they attach importance to and strengthen career planning education, colleges and universities can help students find a suitable career path for their own development, and effectively control the high mobility of talents in the market and the disorder of mobility, so that students can rationally evaluate themselves and give themselves a rational and correct attitude in social life .Historically, colleges and universities have shouldered the important mission of cultural inheritance and talent cultivation. In view of the cultivation of talents useful to the society and the motherland, colleges and universities should enhance their career planning and training for college students from different perspectives and levels, so as to open up new paths for their growth and life development.

\section{References}

[1] Yuan Le, Zhou Waiwei, Dai Minxiu. Comparative research and thinking on career planning at home and abroad [J]. China construction education.2007 (10):45-46

[2] Liu Shuyan. Thoughts on doing a good job in career planning for college students [J]. Exploration of education.2006 (04):78-80

[3] Xiang Xin. Current situation and countermeasures of education career planning for college students [J]. Modern education science.2008 (05):102-103

[4] Long Yi. Problems and countermeasures of college students' career planning [J]. Mental health education 2005 (05-06):124-126

[5] Wang Zebing, Sun Jixiu, Sheng Jin. Difficulties and outlet of career planning for college students [J]. China youth research.2007 (02):66-69

[6] Li Mingliang. Comment on research on career planning of college students [J]. Journal of chongqing university of posts and telecommunications (social science edition).2010 (01):176-180 